\begin{tabular}{|c|c|c|}
\hline \multirow{2}{*}{$\begin{array}{c}\text { Cellular Physiology } \\
\text { and Biochemistry }\end{array}$} & \multicolumn{2}{|c|}{ Cell Physiol Biochem 2019;53:429-438 } \\
\hline & $\begin{array}{l}\text { DOl: } 10.33594 / 000000148 \\
\text { Published online: } 20 \text { August } 2019 \\
\text { Accepted: } 13 \text { Auqust } 2019\end{array}$ & 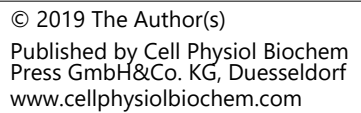 \\
\hline
\end{tabular}

Original Paper

\title{
A Multi-Compartment Model Capturing the Pharmacokinetics of the Calcimimetic Cinacalcet
}

\author{
Gudrun Schappacher-Tilp ${ }^{a}$ Doris H. Fuertinger ${ }^{b}$ Peter Kotanko ${ }^{c, d}$ \\ anniversity of Graz, Institute of Mathematics and Scientific Computing, Graz, Austria, ${ }^{b}$ Fresenius Medical \\ Care Germany, Global Research and Development, Bad Homburg, Germany, 'Renal Research Institute, \\ New York, NY, USA, dIcahn School of Medicine at Mount Sinai, New York, NY, USA
}

\author{
Key Words \\ Cinacalcet $\bullet$ pharmacokinetics $\bullet$ mathematical model
}

\begin{abstract}
Background/Aims: Chronic kidney disease-mineral bone disorder is a major complication affecting the vast majority of chronic kidney disease patients. A hallmark of the disorder is an altered parathyroid gland biology resulting in secondary hyperparathyroidism. This condition is widely treated by calcimimetics like cinacalcet which act by allosteric activation of the calcium sensing receptor. Methods: Here, we present a linear multi-compartment model based on physiological principles such as first-pass metabolism and protein binding, which captures all relevant pharmacokinetic parameters of cinacalcet. Results: Due to the linear structure of the model, simulations are numerically stable and allow fast and accurate short or long-term predictions of cinacalcet concentrations in the body. Conclusion: The model compartments are physiological meaningful and can be easily adjusted to various conditions like impaired hepatic clearance or different drug administration regimens. Moreover, the model can be easily adapted to specific patient groups.

(c) 2019 The Author(s). Published by Cell Physiol Biochem Press GmbH\&Co. KG

\section{Introduction}

Blood ionized calcium concentrations $\left(\mathrm{Ca}^{2+}\right)$ have to be maintained within a very narrow range of around 2\%; a deviation from this range will result in serious health issues and if persistent in life threatening situations [1]. A key endocrine regulator for $\mathrm{Ca}^{2+}$ is the parathyroid hormone (PTH) [2-4]. PTH stimulates bone remodeling thereby ensuring a net release of calcium from the bone storage. Furthermore, it stimulates vitamin D conversion to its metabolic active form 1, 25-dihydroxyvitamin D3, and it inhibits renal phosphate reabsorption while enhancing renal calcium reabsorption. The key regulator for the detection of changes in blood ionized calcium levels and the subsequent secretion of PTH is

Gudrun Schappacher-Tilp $\quad$ Institute of Mathematics and Scientific Computing

University of Graz, Heinrichstraße 36, 8010 Graz (Austria)

Tel. +43 316380 5076, E-Mail gudrun.schappacher-tilp@uni-graz.at
\end{abstract}




\section{Cellular Physiology Cell Physiol Biochem 2019;53:429-438

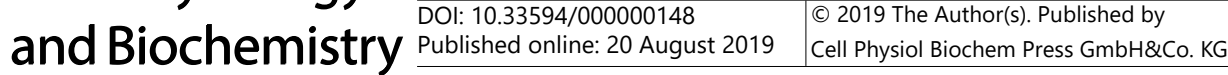 \\ Schappacher-Tilp et al.: A Mathematical Model of Cinacalcet Pharmacokinetics}

the calcium-sensing receptor (CaSR) on the surface of parathyroid gland (PTG) cells [5-7]. If activated by calcium binding, the CaSR down-regulates PTH production and secretion as well as cell proliferation of PTG cells.

In patients suffering from chronic kidney disease (CKD) the impairment of vitamin D metabolism as well as the impaired clearance of PTH and phosphate by the kidneys trigger a cascade of feedback loops resulting eventually in chronic kidney disease-mineral bone disorder (CKD-MBD). CKD-MBD is a complex disorder affecting the vast majority of chronic kidney disease patients. It is associated with a variety of pathological effects like renal osteodystrophy [8-10] or vascular calcification and an increased risk for cardiovascular events, the leading cause of mortality in CKD patients [11-14]. A hallmark of CKD-MBD is secondary hyperparathyroidism, reduced expression of calcium-sensing receptor and parathyroid gland cell hyperplasia [15-18].

The 2017 KDIGO CKD-MBD Guideline Update suggests maintaining intact PTH levels in the range of approximately 2 to 9 times the upper normal limit for the assay [19]. One strategy to reach this goal is to target the CaSR. Calcimimetic drugs like cinacalcet or etelcalcetide enhance the interaction between the ionized calcium concentration $\left(\mathrm{Ca}^{2+}\right)$ and the CaSR by allosteric activation [20]. The higher sensitivity of the CaSR to $\mathrm{Ca}^{2+}$ leads to an inverse relationship between plasma PTH and cinacalcet concentrations. PTH concentration declines after the administration of cinacalcet until it reaches a minimum approximately 2-3 hours after dosing.

Cinacalcet hydrochlorid, which was approved by the FDA in 2004, is widely used in hemodialysis patients [21] and has been listed under the 100 best selling pharmaceuticals world wide in the last years. In addition to secondary hyperparathyroidism in patients with CKD on dialysis, cinacalcet is also approved for the treatment of hypercalcemia in patients with parathyroid carcinoma, and severe hypercalcemia in patients with primary hyperparathyroidism who are unable to undergo parathyroidectomy. Its pharmacokinetics are well established in clinical studies [20,22-26]. Following oral administration the plasma concentration peaks within 2-6 hours. The absolute bio-availability is only between $20-25 \%$ while absorption is close to $100 \%$ indicating a high first-pass metabolism. Since almost $95 \%$ of the drug in the plasma is protein bound, the affect of hemodialysis on the pharmacokinetics of the drug can be neglected [25].

The mechanisms leading to CKD-MBD are many and highly complex. Thus, a multitude of mathematical models were established in order to gain a better understanding of the multidimensional factors controlling the PTH household [27-29] or PTH and bone remodeling [30]. For clinical application any proposed model should be able to predict the state of individual patients and ideally indicate an optimal treatment strategy. Due to the vast clinical use of cinacalcet, a realistic model of CKD-MBD has to feature the use of cinacalcet and its effects. To be of clinical use the cinacalcet model should be readily adaptable to various conditions, such as hepatic impairment enhancing cinacalcet exposure [31]. Moreover, it should be able to reflect different administration scenarios including patient adherence which is known to be poor, due to gastrointestinal side effects and a general high pill load in this patient group [32].

Therefore, the aim of this study was to build a multi-compartment model based on physiological considerations capturing all major pharmacokinetics parameters of cinacalcet. Moreover, the model should allow an intuitive individualization to various conditions or administration regimens and omit any numerical instabilities in order to be easily combined with or incorporated to other physiological models.

\section{Materials and Methods}

\section{Pharmacokinetics}

The low bio-availability of $20-25 \%$ indicates a high first pass metabolism. Hepatic impairment results in higher terminal half-life values (40-70\% for moderate to severe impairment) and higher total 
exposure (2.4 old to 4.2-fold higher in patients with moderate to severe impairment) [31]. Administration with food results in higher bioavailability and consequently higher peak concentrations and total exposure values [32]. Around $95 \%$ of the drug is protein bound. Therefore, the effect of hemodialysis on the pharmacokinetics is negligible [26]. The high volume of distribution at steady state of 1000 liters indicates a vast distribution

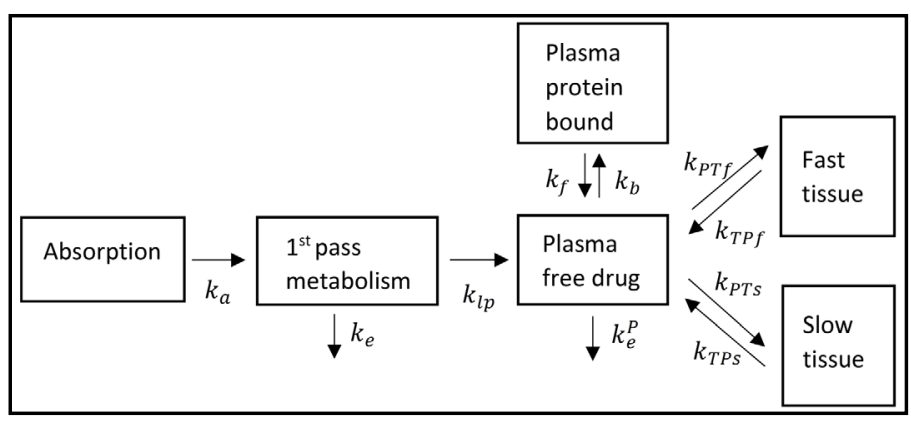

Fig. 1. Pharmacokinetic model of cinacalcet. The absorbed drug has to overcome first pass metabolisms before it enters systemic circulation where it can be bound to protein, eliminated or distributed to the tissue compartments. outside the systemic circulation [33]. Experiments with radioactive labeled cinacalcet have shown that the drug peaks at different times in different tissues. Roughly, tissue can be lumped into two groups: one group with short time to peak and one group with longer time to peak operating like a buffer for cinacalcet [33].

\section{Mathematical model}

The proposed model is depicted in Fig. 1. We use six physiological motivated compartments, i.e. compartments for absorption, first pass metabolism, plasma free drug and protein bound as well as two tissue compartments. It is notable that the tissue compartment with the longer time to peak can be omitted in most situations reducing the system to 5 compartments. The impact of the sixth compartment on the predictions based the parameter set presented in this manuscript is marginal. However, the tissue compartment with longer time to peak includes adipose tissue and adrenals [33]. Therefore, the six compartment model will be useful when addressing patients deviating from the norm regarding adipose tissue or adrenal gland mass. We use constant rate functions between the compartments. The amount of drug in each compartment can be calculated by solving the following system of linear ordinary differential equations:

$$
\frac{d \vec{y}}{d t}=A \cdot \vec{y}
$$

where $\vec{y}_{1}$ corresponds to the amount of drug in the absorption compartment, $\vec{y}_{2}$ to the amount of drug in the first pass metabolism, $\vec{y}_{3}$ and $\vec{y}_{4}$ to the amount of drug in the free and protein bound plasma compartments. $\vec{y}_{5}$ and $\vec{y}_{6}$ correspond to the amount of drug in the fast and slow tissue, respectively. The initial dose is delivered to the absorption compartment. In cinacalcet naïve patients the initial condition is given by the vector $\vec{y}_{0}=(\text { Administered dose, } 0,0,0,0,0)^{\prime}$. In non-naïve patients the condition for a drug administration at time $t_{a}$ is $\vec{y}_{t_{a}}=\vec{y}\left(t_{a}\right)+\vec{y}_{0}$. The coefficient matrix $A$ can be written as

$$
A=\left(\begin{array}{cccccc}
-k_{a} & 0 & 0 & 0 & 0 & 0 \\
k_{a} & -k_{e}-k_{l p} & 0 & 0 & 0 & 0 \\
0 & k_{l p} & -k_{b}-k_{P T f}-k_{P T s}-k_{e}^{P} & k_{f} & k_{T P f} & k_{T P s} \\
0 & 0 & k_{b} & -k_{f} & 0 & 0 \\
0 & 0 & k_{P T f} & 0 & -k_{T P f} & 0 \\
0 & 0 & k_{P T s} & 0 & 0 & -k_{T P s}
\end{array}\right) .
$$




\section{Cellular Physiology Cell Physiol Biochem 2019;53:429-438 \\ \begin{tabular}{c|c|c|} 
and Biochemistry Pol: $10.33594 / 000000148$ & O 2019 The Author(s). Published by \\
\cline { 2 - 3 } Sonline: 20 August 2019 & Cell Physiol Biochem Press GmbH\&Co. KG
\end{tabular} \\ Schappacher-Tilp et al.: A Mathematical Model of Cinacalcet Pharmacokinetics}

This linear system has the distinct advantage that it can be solved by solving the corresponding eigenvalue problem, i.e. if $\lambda_{1}, \ldots, \lambda_{6}$ are the distinct eigenvalues of $A$ and $\Phi=\left(\vec{v}_{1}, \ldots, \vec{v}_{6}\right)$ is a matrix containing the corresponding eigenvectors, then the solution of the differential equation with the last dose administration at time $t_{a}$ is

$$
\vec{y}(t)=\sum_{i=1}^{6}\left(\Phi^{-1} \vec{y}_{t_{a}}{ }^{\prime}\right)_{i} \vec{v}_{i} e^{\lambda_{i} t}, t \geq t_{a} .
$$

Therefore, at any given time $t$ we can calculate the drug amount by evaluating the amount of drug in all compartments only for the preceding administration times. Long time simulations are therefore very fast and numerically stable.

We use data from the literature to estimate the coefficient matrix $A$. The natural constriction is that all eigenvalues should be distinct and negative to ensure the convergence to zero in all compartments in the absence of further drug administrations. We assume an average plasma volume of 3 liters and a single oral dose of $75 \mathrm{mg}$ cinacalcet if not stated otherwise. The target maximum plasma concentration $C_{\max }$ should be close to $26.8 \mathrm{ng} / \mathrm{mL}$, the time until the maximum plasma concentration is reached around 2.3 hours, terminal half-life $t_{1 / 2} 30-40$ hours, distribution half-life $t_{D} 6$ hours [26,33]. The apparent oral clearance rate $C L / F$ which is defined as

$$
C L / F=\frac{(\text { administered dose })}{\int_{0}^{\infty} C(\tau) d \tau}
$$

should be around $314 \mathrm{~L} / \mathrm{h}$ [25]. The apparent volume of distribution at steady state $V_{D}$ which is defined as

$$
V_{D}=(\text { administered dose }) \cdot \frac{\int_{0}^{\infty} t \cdot C(t) d t}{\left(\int_{0}^{\infty} C(t) d t\right)^{2}}
$$

should be around 1000 L [25, 33]. Finally, the bio-availability Bio should be between 20 and 25\% for fastening patients. We calculate the bio availability as

$$
\text { Bio }=\frac{\int_{0}^{\infty} C_{\text {oral }}(t) d t}{\int_{0}^{\infty} C_{i v}(t) d t},
$$

where $C_{i v}$ is the plasma concentration of the intravenously administered drug. We calculate $C_{i v}$ by analyzing the model modified for intravenous bolus injection. The drug is administered to the "Plasma free drug" compartment thereby omitting the absorption and first pass metabolism compartments. $C_{\text {oral }}$ is the plasma concentration of the orally administered drug [25].

\section{Model parameters and sensitivity analysis}

Typical model parameters are given in Table 1 . We set $k_{f}=0.0526 k_{b}$ to ensure that $95 \%$ of the drug is protein bound in the steady state. For simulations regarding food intake we slightly enhance the absorption rate to $k_{a}=0.6 h^{-1}$ in order to accommodate a slightly lower $t_{\max }$ and we reduce the first pass metabolism rate $k_{e}=0.13 h^{-1}$.

Table 1. Model parameters are optimized based on pharmacokinetic data $[26,33]$

\begin{tabular}{ll}
\hline Parameter & Value \\
\hline$k_{a}$ & $0.4 \cdot h^{-1}$ \\
$k_{e}$ & $0.266 \cdot h^{-1}$ \\
$k_{l p}$ & $0.09 \cdot h^{-1}$ \\
$k_{e}^{p}$ & $1 \cdot 30 \cdot h^{-1}$ \\
$k_{b}$ & $1 \cdot 10^{-5} \cdot h^{-1}$ \\
$k_{P T f}$ & $550 \cdot h^{-1}$ \\
$k_{T P f}$ & $0.08 \cdot h^{-1}$ \\
$k_{P T S}$ & $50 \cdot h^{-1}$ \\
$k_{T P S}$ & $1 \cdot 10^{-5} \cdot h^{-1}$ \\
\hline
\end{tabular}




\section{Cellular Physiology Cell Physiol Biochem 2019;53:429-438

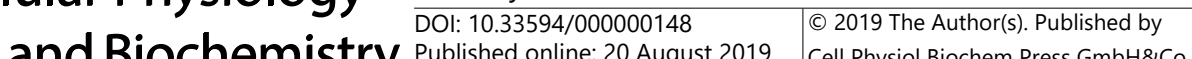 \\ Published online: 20 August 2019 Cell Physiol Biochem Press GmbH\&Co. KG \\ Schappacher-Tilp et al.: A Mathematical Model of Cinacalcet Pharmacokinetics}

We conducted a sensitivity analysis to study the impact of uncertainties in all parameters in the coefficient matrix $A$ and to identify key parameters of inter-individual variability. The base values of each of these parameters was either divided or multiplied by a factor of 2 . We then calculated the respective pharmacokinetic parameters assuming a single dose administration of $60 \mathrm{mg}$ cinacalcet. We compared these values to the corresponding base case values. The results are presented in Table 2 . The analysis reveals that bio-availability is most sensitive to changes of $k_{e}$ and $k_{l p}$. Accordingly, $C_{\max }$ is most sensitive to changes of $k_{e}, k_{l p}$. Moreover, $C_{\text {max }}$ is sensitive to changes of $k_{P T f}$ which determines the buffer function of the tissue. Due to the buffer function of the tissue compartments the terminal half-life is most sensitive to changes of $k_{P T f}, k_{P T S}$ and $k_{P T S}$. The half-life of distribution as well as $t_{\text {max }}$ are sensitive to changes in $k_{b}$ and $k_{e}$. Due to its definition, the apparent oral clearance rate $C L / F$ is only sensitive to changes in $k_{e}$ and $k_{l p}$.

\section{Adaptation to specific patient groups}

The model can be personalized to individual patients by adjusting the various parameters based on the physiological meaning of the compartments and the sensitivity analysis. As an example we aim to adjust the model to patients with hepatic impairment. It is known that the area under the curve $A U C_{\infty}$ is 2.4 and 4.2 fold higher in patients with moderated and severe hepatic impairment, respectively, than in healthy control patients. Terminal half-life $t_{1 / 2}$ is 1.3 and 1.7 fold higher in patients with moderated and severe hepatic impairment, respectively, than in healthy control patients. $C_{\max }$ and $t_{\max }$ are not significantly altered [31]. The rates associated with liver function are the first pass metabolism rates $k_{e}$ and $k_{l p}$ as well as the elimination rate $k_{e}^{P}$ which is associated with metabolization of the drug by the liver.

Since $C_{\max }$ and $t_{\max }$ are most sensitive to changes in $k_{e}$ and $k_{p l}$, these parameters should not be adjusted. While target $A U C$ and $t_{1 / 2}$ levels could be reached by adjusting the protein binding rate or the transfer rate to the tissue compartments, the meaningful rate to adjust is $k_{e}^{P}$. We can use the linear structure of the model to calculate the area under the curve $A U C_{\infty}$ :

$$
A U C_{\infty}=\int_{0}^{\infty} C(\tau) d \tau=-\left(\sum_{i=1}^{6}\left(\frac{1}{\lambda_{i}} \Phi^{-1} \vec{y}_{0}^{\prime}\right)_{i} \vec{v}_{i}\right)_{3}-\left(\sum_{i=1}^{6}\left(\frac{1}{\lambda_{i}} \Phi^{-1} \vec{y}_{0}^{\prime}\right)_{i} \vec{v}_{i}\right)_{4}
$$

where the subscripts 3 and 4 denote the third and fourth vector component, respectively. Furthermore, we can use the linear structure of the model to estimate terminal half-life which is associated with the tissue compartments and the largest eigenvalues. Since the fast tissue compartment dominates, we can use the largest eigenvalue $\lambda_{k}$ associated with the fast tissue compartment:

$$
t_{1 / 2} \approx \frac{\ln (0.5)}{\lambda_{k}}
$$

With the parameters set presented in Table 1 the difference between the exact value and the approximated value is less then $0.01 \%$. The reduction of $k_{l}^{P}$ by $53 \%$ enhances the terminal half-life 1.4 fold and the $A U C_{\infty} 2.2$-fold, the reduction of $k_{l}^{P}$ by $76 \%$ enhances the terminal half-life 1.8 fold and the $A U C_{\infty}$ 4.2-fold.

Another example would be the administration with food. It has been shown that the administration of a single dose of $90 \mathrm{mg}$ cinacalcet with high fat and low fat meal enhances the bio-availability significantly resulting in increase of $A U C_{\infty}$ of $68 \%$ (90\% confidence interval: $48 \%$ to $89 \%$ ) and $50 \%$ (90\% confidence interval: $33 \%$ to $70 \%$ ), respectively [25]. Mean $t_{\max }$ is higher in fastening subjects (6h) then in subjects receiving cinacalcet with a high fat diet $(4 \mathrm{~h})$ and a low fat diet (3.5h). Terminal half-life was comparable between the administration schemes. Since bio-availability is associated with absorption and first-pass 
metabolism, the only meaningful parameters to adjust are $k_{a}, k_{e}$ and $k_{l p}$. The sensitivity analysis suggests to decrease $k_{e}$ and/or increase $k_{l p}$. Since an increase in $k_{e}$ would lead to an increase of $t_{\max }$ we adjust only $k_{l p}$.

\section{Results}

\section{Main pharmacokinetics profiles}

The simulated pharmacokinetics profile of a single oral administration based on the proposed six-compartment model is shown in Fig. 2 and Fig. 3. The results are qualitatively and quantitatively in close agreement with published clinical data.

Table 2. Sensitivity analysis of all estimated model parameters. The base case values where either divided or multiplied by 2 . The values, which are rounded to one digit, are the differences to the base cap predictions

\begin{tabular}{lccccccc}
\hline Parameter & $\begin{array}{c}C_{\max } \\
{[\mathrm{ng} / \mathrm{ml}]}\end{array}$ & $\begin{array}{c}t_{\max } \\
{[h]}\end{array}$ & $\begin{array}{c}\text { Bio } \\
{[\%]}\end{array}$ & $\begin{array}{c}t_{1 / 2} \\
{[h]}\end{array}$ & $\begin{array}{c}t_{1 / 2}^{D} \\
{[h]}\end{array}$ & $\begin{array}{c}V D \\
{[L]}\end{array}$ & $\begin{array}{c}C L / F \\
{[L / h]}\end{array}$ \\
\hline Base line & 25.6 & 3.1 & 22.8 & 35.2 & 6 & 1056 & 339 \\
$k_{a} \cdot 0.5 / \cdot 2$ & $-7.1 / 7$ & $1.6 /-1.1$ & $0 / 0$ & $-0.3 / 0$ & $5.0 /-2$ & $62.6 /-32.9$ & $0 / 0$ \\
$k_{e} \cdot 0.5 / \cdot 2$ & $6.9 /-7.1$ & $0.9 /-0.9$ & $13.6 /-9.7$ & $-0.1 / 0$ & $3.2-/ 1.9$ & $368 / 734$ & $-206 / 696$ \\
$k_{l p} \cdot 0.5 / \cdot 2$ & $-11.9 / 19.5$ & $0.3 /-0.4$ & $-9.7 / 13.6$ & $0 / 0$ & $0.7 /-0.9$ & $807 /-403$ & $696 /-206$ \\
$k_{e}^{p} \cdot 0.5 / \cdot 2$ & $1 /-1.8$ & $0 / 0$ & $0 / 0$ & $4.2 /-5.8$ & $0.2 /-0.3$ & $192 /-273$ & $0 / 0$ \\
$k_{P T f} \cdot 0.5 / \cdot 2$ & $0 / 0$ & $0 / 0$ & $0 / 0$ & $0 / 0$ & $0 / 0$ & $0.5 /-0.3$ & $0 / 0$ \\
$k_{\text {TPf }} \cdot 0.5 / \cdot 2$ & $-1.5 / 3.3$ & $-0.3 / 0.6$ & $0 / 0$ & $35.2 /-17.6$ & $-1.4 / 3$ & $-175 /-13$ & $0 / 0$ \\
$k_{P T S} \cdot 0.5 / \cdot 2$ & $14.4 /-10.7$ & $-0.1 / 0$ & $0 / 0$ & $-13.2 / 26.5$ & $-0.8 / 0.8$ & $-208 /-27$ & $0 / 0$ \\
$k_{\text {TPS }} \cdot 0.5 / \cdot 2$ & $0 / 0$ & $0 / 0$ & $0 / 0$ & $0 / 0$ & $0 / 0$ & $0 / 0$ & $0 / 0$ \\
\hline
\end{tabular}

Fig. 2. Cinacalcet concentration versus time after a single $75 \mathrm{mg}$ dose. The mean reference values for $C_{\max }$ is $26.6 \mathrm{ng} / \mathrm{mL}$ (9.4 SD), the reference range for $t_{\max }$ is 1-6 hours, for bio-availability ( $\mathrm{Bio}$ ) 20-25\%, and for volume of distribution (VD) 1000-1250 L [25,33]. The reference value for the mean apparent oral clearance rate $(C L / F)$ is $314 \mathrm{~L} / \mathrm{h}$ (148 SD) [25].

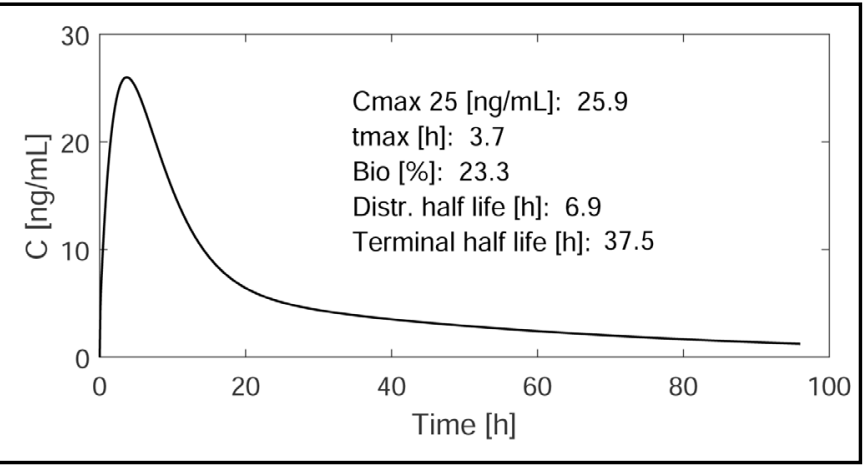

Fig. 3. Cinacalcet concentration versus time after a single $75 \mathrm{mg}$ dose (solid line) and the exponential fits used for half-life estimation (dotted lines) on a logarithmic scale. The reference value for the half-life of distribution $t_{1 / 2}^{D}$ is 6 hours, the reference range for the terminal half-life is $30-40$ hours [25, 33].

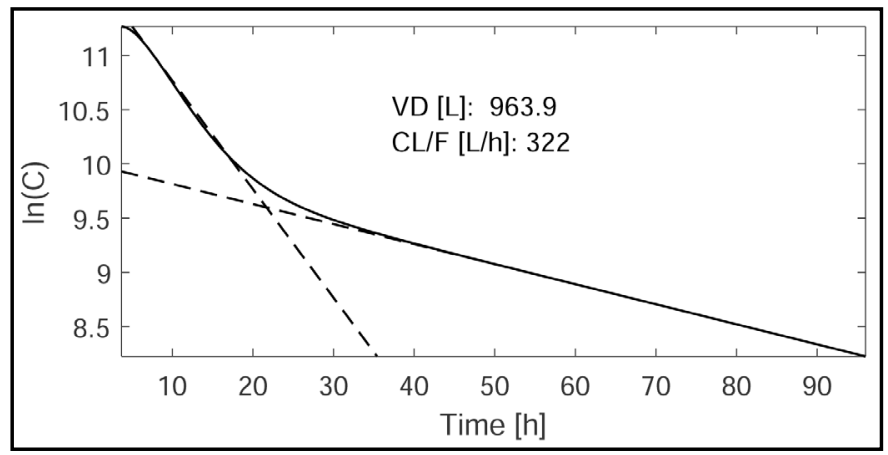


Fig. 4. Cinacalcet concentration versus time based on the assumption that $75 \mathrm{mg}$ cinacalcet is administered every 24 hours [25].

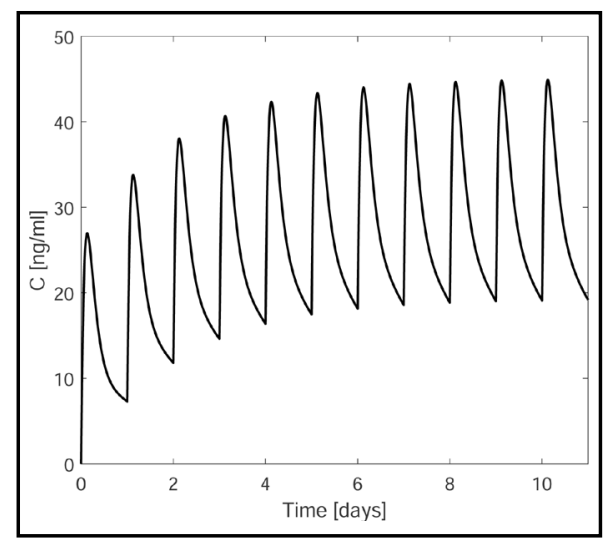

Fig. 5. Drug profiles in cinacalcet naïve patients (upper panel) and in patients after a 12 weeks run in phase (lower panel). While the optimal daily administration leads to higher exposure, reliable three times a week administration is not inferior to a daily administration scheme considering a more realistic adherence rate.
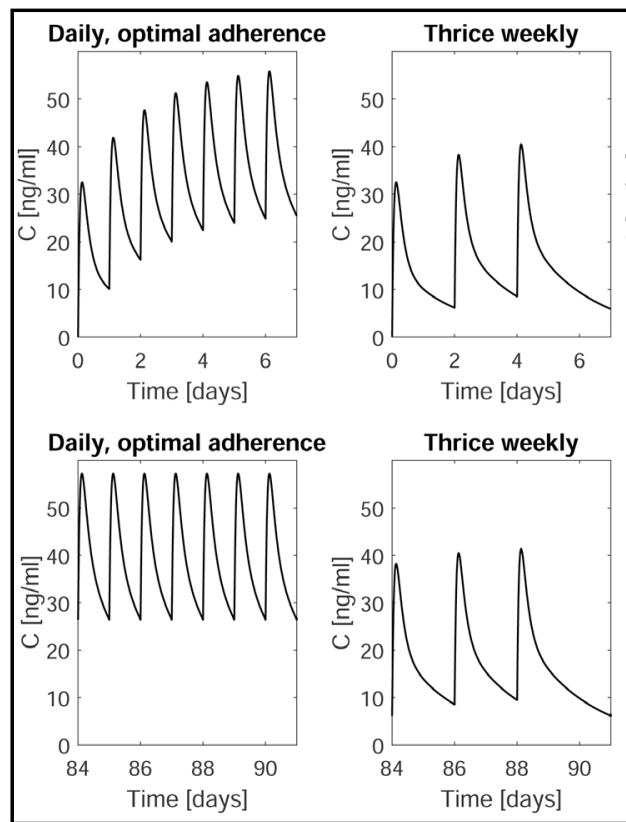
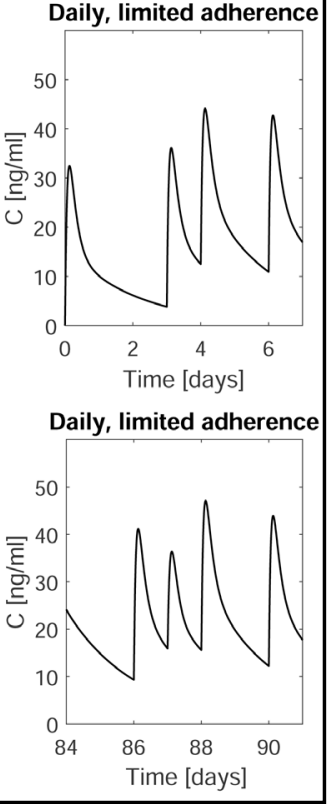

The simulations of daily administration of cinacalcet predict a steady state within seven days (Fig. 4) which is similar to clinically observed behavior of the drug [33].

\section{Different dosing regimens}

To assess the impact of dosing regimens on the total exposure we modeled the weekly average cinacalcet concentration in the blood for three different dosing regimens: daily administration, administration three times a week, and administration with a realistic medication refill rate of $64 \%$ [34]. For the realistic medication refill rate scenario we chose days without administration randomly (Fig. 5).

\section{Discussion}

The linear multi-compartment model introduced in this article is used to describe the complex pharmacokinetic behavior of cinacalcet in the human body. This approach allows the analysis of the effect of different dosing regimens on the drug concentration in 


\section{Cellular Physiology Cell Physiol Biochem 2019;53:429-438 \\ \begin{tabular}{c|c|c} 
and Biochemistry POl: 10.33594/000000148 & O 2019 The Author(s). Published by \\
\cline { 2 - 3 } Sonline: 20 August 2019 & Cell Physiol Biochem Press GmbH\&Co. KG
\end{tabular} \\ Schappacher-Tilp et al.: A Mathematical Model of Cinacalcet Pharmacokinetics}

the body that could otherwise only be addressed by clinical studies. The analysis can help to evaluate dose titration and administration schemes. Calcium homeostasis in the human body is achieved by a complex network of regulators, one of them being the kidney. If the kidney function starts to decline, a cascade of physiological processes eventually result in secondary hyperparathyroidism. Due to the complexity of the system, a growing number of mathematical models have been published with the aim to analyze the driving factors of calcium homeostasis, secondary hyperparathyroidism, and CKD-MBD [27, 29, 30, 3538]. However these models did not include a detailed model of cinacalcet, a drug widely prescribed in patients with secondary hyperparathyroidism. Our pharmacokinetic model can be easily incorporated in all other models by using an operational model of allosterism which transfers the actual $\mathrm{Ca}^{2+}$ concentration by the amount of free drug in the plasma [3941].

It is worth noticing that many model approaches with more than one compartment are able to predict one or two pharmacokinetics parameter within a desired range. The model introduced in this article is minimal in the sense that a linear mass-balance model with less than five compartments is not able to capture all seven key pharmacokinetic parameters (i.e. $C_{\max }, t_{\max }, B i o, C L / F, t_{1 / 2}, t_{1 / 2}^{D}$, and $V D$ ) simultaneously.

\section{Conclusion}

In conclusion, we have developed a mathematical model incorporating key components of cinacalcet pharmacokinetics. A great advantage of this model is its linear structure allowing long term predictions which are fast and numerically stable. The model is a general compartment model which could be used to evaluate different drugs. An example would be etelcalcetide, another calcimimetic which is administered intravenously [42]. In this case the model reduces to a four compartment model since the intestinal absorption and first-pass metabolism compartments are obsolete. Due to the physiological meaningful compartments, adjustments to conditions like hepatic impairment are straight forward. Combined with a model for the parathyroid gland and bone metabolism it provides a ready to use tool for clinical trial simulations to explore effects of relevant factors, such as patient adherence, off-label administration regimens, or the effect of administration combined with food intake.

\section{Acknowledgements}

The funding for this study came from Renal Research Institute, a wholly owned subsidiary of Fresenius Medical Care.

\section{Disclosure Statement}

Peter Kotanko holds stock in Fresenius Medical Care. The other authors have no conflicts of interest to declare. 


\section{Cellular Physiology Cell Physiol Biochem 2019;53:429-438 \begin{tabular}{l|l|l}
\hline DOI: 10.33594/000000148 & (c)19 The Author(s). Published by
\end{tabular} and Biochemistry Published online: 20 August $2019 \quad$ Cell Physiol Biochem Press GmbH\&Co. KG \\ Schappacher-Tilp et al.: A Mathematical Model of Cinacalcet Pharmacokinetics}

\section{References}

1 Brown EM: Clinical lessons from the calcium-sensing receptor. Nat Clin Pract Endocrinol Metab 2007;3:122-133.

2 Pocotte S, Ehrenstein G, Fitzpatrick L: Regulation of Parathyroid-Hormone Secretion. Endocr Rev 1991;12:291-301.

3 Silver J, Moallem E, Kilav R, Epstein E, Sela A, NavehMany T: New insights into the regulation of parathyroid hormone synthesis and secretion in chronic renal failure. Nephrol Dial Transplant 1996;11:2-5.

$4 \quad$ Nemeth E: Pharmacological regulation of parathyroid hormone secretion. Curr Pharm Des 2002;8:20772087.

5 Conigrave AD, Ward DT: Calcium-sensing receptor (CaSR): Pharmacological properties and signaling pathways. Best Pract Res Clin Endocrinol Metab 2013;27:315-331.

6 Chakravarti B, Chattopadhyay N, Brown EM: Signaling Through the Extracellular Calcium-Sensing Receptor (CaSR). Adv Exp Med Biol 2012;740:103-142.

7 Chen R, Goodman W: Role of the calcium-sensing receptor in parathyroid gland physiology. Am J Physiol Renal Physio 2004;286:F1005-1011.

8 Jadoul M, Albert JM, Akiba T, Akizawa T, Arab L, Bragg-Gresham JL, Mason N, Prutz KG, Young EW, Pisoni RL: Incidence and risk factors for hip or other bone fractures among hemodialysis patients in the Dialysis Outcomes and Practice Patterns Study. Kidney Int 2006;70:1358-1366.

9 Nickolas TL, Leonard MB, Shane E: Chronic kidney disease and bone fracture: a growing concern. Kidney Int 2008;74:721-731.

10 Stehman-Breen CO, Sherrard DJ, Alem AM, Gillen DL, Heckbert SR, Wong CS, Ball A, Weiss NS: Risk factors for hip fracture among patients with end-stage renal disease. Kidney Int 2000;58:2200-2205.

11 Raggi P, Boulay A, Chasan-Taber S, Amin N, Dillon M, Burke SK, Chertow GM: Cardiac calcification in adult hemodialysis patients - A link between end-stage renal disease and cardiovascular disease? J Am Coll Cardiol 2002;39:695-701.

12 Cheung AK, Sarnak MJ, Yan GF, Dwyer JT, Heyka RJ, Rocco MV, Teehan BP, Levey AS: Atherosclerotic cardiovascular disease risks in chronic hemodialysis patients. Kidney Int 2000;58:353-362.

13 Palmer SC, Hayen A, Macaskill P, Pellegrini F, Craig JC, Elder GJ, Strippoli GF: Serum levels of phosphorus, parathyroid hormone, and calcium and risks of death and cardiovascular disease in individuals with chronic kidney disease A systematic review and meta-analysis. Jama 2011;305:1119-1127.

14 Melamed ML, Eustace JA, Plantinga L, Jaar BG, Fink NE, Coresh J, Klag MJ, Powe NR: Changes in serum calcium, phosphate, and PTH and the risk of death in incident dialysis patients: A longitudinal study. Kidney Int 2006;70:351-357.

15 Gonzalez EA, Sachdeva A, Oliver DA, Martin KJ: Vitamin D insufficiency and deficiency in chronic kidney disease - A single center observational study. Am J Nephrol 2004;24:503-510.

16 Levin A, Bakris GL, Molitch M, Smulders M, Tian J, Williams LA, Andress DL: Prevalence of abnormal serum vitamin D, PTH, calcium, and phosphorus in patients with chronic kidney disease: Results of the study to evaluate early kidney disease. Kidney Int 2007;71:31-38.

17 Martin KJ, Gonzalez EA: Metabolic bone disease in chronic kidney disease. J Am Soc Nephrol 2007;18:875-885.

18 Block GA, Port FK: Re-evaluation of risks associated with hyperphosphatemia and hyperparathyroidism in dialysis patients: Recommendations for a change in management. Am J Kidney Dis 2000;35:12261237.

19 Ketteler M, Block GA, Evenepoel P, Fukagawa M, Herzog CA, McCann L, Moe SM, Shroff R, Tonelli MA, Toussaint ND, Vervloet MG, Leonard MB: Executive summary of the 2017 KDIGO Chronic Kidney DiseaseMineral and Bone Disorder (CKD-MBD) Guideline Update: what's changed and why it matters. Kidney Int 2017;92:26-36.

20 Valle C, Rodriguez M, Santamaria R, Almaden Y, Rodriguez ME, Canadillas S, Martin-Malo A, Aljama P: Cinacalcet Reduces the Set Point of the PTH-Calcium Curve. J Am Soc Nephrol 2008;19:2430-2436.

21 Block G, Martin K, de Francisco A, Turner S, Avram M, Suranyi M, Hercz G, Cunningham J, Abu-Alfa AK, Messa P, Coyne DW, Locatelli F, Cohen RM, Evenepoel P, Moe SM, Fournier A, Braun J, McCary LC, Zani VJ, Olson KA, et al.: Cinacalcet for secondary hyperparathyroidism in patients receiving hemodialysis. N Engl J Med 2004;350:1516-1525. 


\section{Cellular Physiology Cell Physiol Biochem 2019;53:429-438 \begin{tabular}{l|l|l}
\hline DOI: 10.33594/000000148 & (c)19 The Author(s). Published by
\end{tabular} and Biochemistry Published online: 20 August $2019 \quad$ Cell Physiol Biochem Press GmbH\&Co. KG \\ Schappacher-Tilp et al.: A Mathematical Model of Cinacalcet Pharmacokinetics}

22 Dong BJ: Cinacalcet: An oral calcimimetic agent for the management of hyperparathyroidism. Clin Ther 2005;27:1725-1751.

23 Kumar GN, Sproul C, Poppe L, Turner S, Gohdes M, Ghoborah H, Padhi D, Roskos L: Metabolism and disposition of calcimimetic agent cinacalcet HCL in humans and animal models. Drug Metab Dispos 2004;32:1491-1500.

24 Moe SM, Chertow GM, Coburn JW, Quarles LD, Goodman WG, Block GA, Drüeke TB, Cunningham J, Sherrard DJ, McCary LC, Olson KA, Turner SA, Martin KJ: Achieving NKF-K/DOQI (TM) bone metabolism and disease treatment goals with cinacalcet HCl. Kidney Int 2005;67:760-771.

25 Padhi D, Harris R: Clinical Pharmacokinetic and Pharmacodynamic Profile of Cinacalcet Hydrochloride. Clin Pharmacokinet 2009;48:303-311.

26 Harris R, Padhi D, Marbury T, Noveck R, Salfi M, Sullivan J: Pharmacokinetics, pharmacodynamics, and safety of cinacalcet hydrochloride in hemodialysis patients at doses up to $200 \mathrm{mg}$ once daily. Am J Kidney Dis 2004;44:1070-1076.

27 Shrestha RP, Hollot CV, Chipkin SR, Schmitt CP, Chait Y: A mathematical model of parathyroid hormone response to acute changes in plasma ionized calcium concentration in humans. Math Biosci 2010;226:4657.

28 Schappacher-Tilp G, Cherif A, Fuertinger DH, Bushinsky D, Kotanko P: A mathematical model of parathyroid gland biology. Physiol Rep 2019;7:e14014.

29 Raposo JF, Pires A, Yokota H, Ferreira HG: A mathematical model of calcium and phosphorus metabolism in two forms of hyperparathyroidism. Endocrine 2012;41:309-319.

30 Peterson MC, Riggs MM: A physiologically based mathematical model of integrated calcium homeostasis and bone remodeling. Bone 2010;46:49-63.

31 Padhi D, Harris RZ, Salfi M, Noveck RJ, Sullivan JT: Pharmacokinetics and pharmacodynamics of cinacalcet in hepatic impairment - Phase I, open-label, parallel-group, single-dose, single-centre study. Clinical Drug Investig 2008;28:635-643.

32 Padhi D, Salfi M, Harris RZ: The pharmacokinetics of cinacalcet are unaffected following consumption of high- and low-fat meals. Am J Ther 2007;14:235-240.

33 Food and Drug Administration, Center for Drug Evaluation and Research: Application Number: 21-688, Pharmacological Review. Sensipar.

URL: http://www.accessdata.fda.gov/drugsatfda_docs/nda/2004/21-688.pdf_Sensipar_Pharmr_P1.pdf

34 Gincherman Y, Moloney K, McKee C, Coyne DW: Assessment of adherence to cinacalcet by prescription refill rates in hemodialysis patients. Hemodial Int 2010;14:68-72.

35 Granjon D, Bonny 0, Edwards A: Coupling between phosphate and calcium homeostasis: a mathematical model. Am J Physiol Renal Physiol 2017;313:F1181-1199.

36 Brown E: 4-Parameter Model of the Sigmoidal Relationship between Parathyroid-Hormone Release and Extracellular Calcium-Concentration in Normal and Abnormal Parathyroid Tissue. J Clin Endocrinol Metab 1983;56:572-581.

37 Christie CR, Achenie LEK, Ogunnaike BA: A Control Engineering Model of Calcium Regulation. J Clin Endocrinol Metab 2014;99:2844-2853.

38 Raposo J, Sobrinho L, Ferreira H: A minimal mathematical model of calcium homeostasis. J Clin Endocrinol Metab 2002;87:4330-4340.

39 Leach K, Loiacono RE, Felder CC, McKinzie DL, Mogg A, Shaw DB, Sexton PM, Christopoulos A: Molecular Mechanisms of Action and In Vivo Validation of an M-4 Muscarinic Acetylcholine Receptor Allosteric Modulator with Potential Antipsychotic Properties. Neuropsychopharmacology 2010;35:855-869.

40 Leach K, Gregory KJ, Kufareva I, Khajehali E, Cook AE, Abagyan R, Conigrave AD, Sexton PM, Christopoulos A: Towards a structural understanding of allosteric drugs at the human calcium-sensing receptor. Cell Res 2016;26:574-592.

41 Leach K, Sexton PM, Christopoulos A: Allosteric GPCR modulators: taking advantage of permissive receptor pharmacology. Trends Pharmacol Sci 2007;28:382-389.

42 Block GA, Bushinsky DA, Cheng S, Cunningham J, Dehmel B, Drueke TB, Ketteler M, Kewalramani R, Martin KJ, Moe SM, Patel UD, Silver J, Sun Y, Wang H, Chertow GM: Effect of Etelcalcetide vs Cinacalcet on Serum Parathyroid Hormone in Patients Receiving Hemodialysis With Secondary Hyperparathyroidism A Randomized Clinical Trial. Jama 2017;317:156-164. 